\title{
MAKNA IKINSAI DALAM MIEMPU BUYUK SUKU DAYAK MA'ANYAN
}

\author{
Oleh: \\ Emma Tianna Riantri \\ Pembimbing Tugas Akhir: Dr. Ni Nyoman Sudewi, S.S.T., M.Hum. dan \\ Dra. M. Heni Winahyuningsih, M.Hum. \\ Jurusan Tari, Fakultas Seni Pertunjukan, Institut Seni Indonesia Yogyakarta \\ Alamat email : emmariantrifad@gmail.com
}

\section{Ringkasan}

Міетри Виуиk merupakan istilah untuk menyebut upacara ritual pengobatan suku Dayak Ma'anyan. Miетри Buyuk dipimpin oleh Wadian Dadas. Miempи Buyuk tidak dapat dilaksanakan tanpa ada seseorang yang sakit, yang datang juga hadir dalam ritual ini. Salah satu elemen terpenting, yaitu gerak yang dilakukan oleh Wadian Dadas disebut dengan ikinsai. Ikinsai dapat disebut tari, karena gerak-gerak yang dilakukan menunjukkan gerak extraordinary. Wadian Dadas mengalami itun alah (kerasukan roh leluhur) untuk mengambil tumbuhan sebagai obat bagi yang sakit.

Proses pengobatan dalam Міетри Виуиk mencerminkan sebuah ritus peralihan. Meminjam konsep dari Victor Turner, ritus peralihan dibagi ke dalam tiga bagian, yakni separation (pemisahan), transition (liminal), dan reintegration (penyatuan kembali). Ritus peralihan akan membawa ke persoalan liminoid. Pelaksanaan Міетри Виуиk akan mengubah seseorang dari satu situasi ke situasi lainnya. Proses ini akan membawa pelaku, perlengkapan, dan tempat ritual untuk mengalami kebaruan. Elemen-elemen ini akan mengalami masa pemisah, dan berada dalam situasi ambang saat Wadian Dadas melakukan proses penyembuhan. Setelah orang sakit berhasil disembuhkan, semua elemen akan kembali pada posisi awal. Ketika proses penyembuhan, Wadian Dadas selalu ikinsai.

Miempи Buyuk suku Dayak Ma'anyan membuktikan adanya peralihan yang dialami pada ritual itu sendiri dan elemen-elemennya. Peralihan yang dialami Miempu Buyuk menjadi bukti bahwa ada ikinsai yang dimaknai sebagai liminoid. Pada setiap tahapan dari Miempu Buyuk, ikinsai oleh Wadian Dadas berbeda-beda, tetapi ada kesamaan pada pemanfaatan properti. Melalui penelitian ini, diharapkan dapat menambah pengetahuan tentang ikinsai dalam Miempu Buyuk.

\section{Kata Kunci: Miempu Buyuk, Ikinsai, Ritus Peralihan}




\section{ABSTRACT \\ The Intepretation of Ikinsai in Miempu Buyuk Ma'anyan Dayak Tribe}

Miетри Buyuk is a term referring to the treatment ritual ceremony of Ma'anyan Dayak Tribe. Miempu Buyuk, led by a wadian dadas, cannot be held without the presence of the sick, participants, and audiences. One of the crucial elements in the ceremony is movements performed by the wadian dadas called Ikinsai. Ikinsai is actually a dance, as the movements performed indicate extraordinary movements. The wadian dadas experiences an itun alah (possession by ancestor spirits) and picks a plant to cure the sick.

In Miempu Buyuk, the treatment process reflects a rites of passage. Referring to the concept by Victor Turner, the rite was divided into three, separation, transition, and reintegration. It brings someone to liminoid businesses. Miempu Buyuk will transfer someone from one situation to another situation. This process will bring the actors, equipment, and ritual site to a novelty. These elements will undergo a separation period and finally come to a transition situation when the wadian didas conducts a treatment process. After the sick is successfully healed, all elements will return to their previous position. During the healing process, the wadian didas performs Ikinsai continuously.

Miempu Buyuk of Ma'anyan Dayak Tribe proves that there is a shift in the ritual and its elements. It is a proof that Ikinsai interpreted as liminoid. In each stage of Miempu Buyuk, there are many diverse movements in Ikinsai performed by the wadian didas, but there is a similarity in property utilization. Finally, this research is expected to broaden the readers' knowledge of Ikinsai in Miempu Buyuk.

Keywords: Miempu Buyuk, Ikinsai, Rites of Passage 


\section{PENDAHULUAN}

Ma'anyan merupakan salah satu suku dari sub-suku Dayak yang berada di Kalimantan Tengah. Suku Dayak Ma'anyan sebagian besar menetap dan bermukim di dua kabupaten yang berada di Kalimantan Tengah yakni, Kabupaten Barito Timur dan Kabupaten Barito Selatan. Masyarakat suku Dayak Ma'anyan di Kabupaten Barito Timur, tepatnya di Desa Dorong, Tamiang Layang masih banyak yang melakukan kegiatan ritual peninggalan nenek moyang. Ritual yang dilakukan oleh masyarakat suku Dayak Ma'anyan pada umumnya tidak terlepas dari kepercayaan Kaharingan. Kaharingan adalah kepercayaan yang dianut dan diyakini masyarakat sebelum agama lain diajarkan di Kalimantan. Kepercayaan Kaharingan saat ini sudah dikategorikan sebagai bagian dari agama Hindu dan biasa disebut juga dengan Hindu Kaharingan. ${ }^{1}$ Miempu merupakan istilah yang digunakan masyarakat Ma'anyan untuk menyebutkan upacara ritual yang dilakukan oleh Wadian Dadas. Berbagai macam ritual dilakukan secara turun temurun oleh masyarakat suku Dayak Ma'anyan. Ritual dalam siklus kehidupan masyarakat suku Dayak Ma'anyan meliputi, Miempu Numang Wadian, Miempu Nahur Hajat, dan Miempu Buyuk.

${ }^{1}$ Tjilik Riwut, 2003, Manaser Panatau Tatu Hiang, Palangka Raya: Pusakalima, 456.
Miempu Buyuk merupakan upacara ritual pengobatan untuk mengobati penyakit yang bersifat non medis. Міетри Виуиk dapat berlangsung sehari maupun selama beberapa hari. Berlangsungnya Miempu Buyuk melibatkan elemen-elemen pendukung yang saling berkaitan, antara lain pelaku ritual, perlengkapan ritual, dan tempat ritual. Pelaku ritual, yaitu Wadian Dadas, orang sakit, panganak hiang, pemusik, pemimpin kebaktian Kaharingan, dan masyarakat setempat. Perlengkapan ritual terdiri dari sesaji-sesaji, pakaian, dan peralatan lainnya, sedangkan tempat ritual terdiri dari rumah, halaman rumah, dan hutan.

Wadian Dadas adalah pelaku utama dalam pelaksanaan Miempu Buyuk. Dalam melakukan Miempu Buyuk untuk mengobati orang sakit, Wadian Dadas menggunakan perlengkapan, bekerja sama dengan masyarakat dan pelaku lainnya, dan melakukan ikinsai. Ikinsai merupakan salah satu elemen penting yang dihadirkan oleh Wadian Dadas. Wadian Dadas melakukan ikinsai bahwa ikinsai juga ada keterkaitan dengan orang sakit, pemusik, perlengkapan ritual, dan tempat ritual.

Dalam perspektif peneliti, struktur penyajian Miempu Buyuk terdiri dari awal, perkembangan (inti), dan akhir. Мiетри Buyuk ini dimulai dengan kebaktian Kaharingan, dan Wadian Dadas mengenakan 
segala perlengkapan untuk melakukan 'pemanggilan' roh leluhur. Kemudian, dilanjutkan dengan inti dari ritual yakni, bagian penyembuhan dengan Wadian Dadas mengalami itun alah untuk mengambil obat, dan melalui prosesi tiga balai. Setelah itu, diakhiri bagian penutup dengan 'mengembalikan' roh leluhur dan membersihkan segala peralatan. Pada pelaksanaan Мiетри Buyuk ini ada keterlibatan antara pemusik, musik, dan alat musik.

Ikinsai muncul dari bagian awal sampai bagian akhir. Ikinsai pada bagian awal, yakni pada bagian pembukaan, saat Wadian Dadas menaburkan beras ke beberapa pelaku ritual. Ikinsai dilakukan pada bagian pembukaan sebanyak tujuh kali. Pada bagian inti dari ritual, ikinsai berhubungan dengan peristiwa pengobatan saat Wadian Dadas akan mengalami itun alah dan saat melakukan prosesi tiga balai. Ikinsai saat prosesi tiga balai dilakukan oleh Wadian Dadas pada balai Saruga, balai Akar Jawa, dan balai Papai. Terakhir, pada bagian penutup, ikinsai juga ada kaitannya dengan proses 'pengembalian' atau 'memulangkan' roh leluhur ke alamnya. Ikinsai muncul dalam setiap tahap yang akan dilalui dalam Miempu Buyuk.

Proses Miempu Buyuk adalah suatu ritual untuk menyembuhkan seseorang dari yang sakit menjadi tidak sakit. Peristiwa pengobatan dilakukan secara non-fisik dan spriritual yang melibatkan roh leluhur. Wadian Dadas dalam pelaksanaan Miempи Buyuk melakukan ikinsai sebagai salah satu perantara untuk berhubungan dengan roh leluhur. Setiap elemen yang ada saling berkaitan satu sama lain di dalam pelaksanaan Міетри Buуик. Wadian Dadas akan dibantu roh leluhur menemukan obat untuk menyembuhkan orang sakit. Peristiwa pengobatan ini dipandang sebagai ritus peralihan. Seseorang akan beralih dari situasi sakit menjadi situasi sembuh. Perubahan yang dialami elemen-elemen Miempu Buyuk dapat dilihat melalui tahapan peristiwa yang dilalui. Berjalannya Мiетри Buyuk secara keseluruhan akan menunjukkan peralihan dari setiap tahap ke tahap berikutnya.

Ritus peralihan merupakan suatu peristiwa yang memiliki pola tahapan-tahapan ritual. Turner menyatakan bahwa ritus peralihan merupakan peristiwa sosial melalui tiga tahap yakni, pemisahan, liminal, dan penyatuan. ${ }^{2}$ Pemisahan adalah suatu proses yang ditandai masa perpisahan dari posisi lama dalam waktu normal. Liminal merupakan suatu situasi ambang, yaitu suatu situasi yang tidak berada di dalam posisi lama, tetapi belum berada di posisi baru. Penyatuan terjadi ketika situasi yang telah melewati masa

\footnotetext{
${ }^{2}$ Lono Simatupang, 2013, Pergelaran: Sebuah Mozaik Penelitian Seni-Budaya, Yogyakarta, Jalasutra, 110.
} 
ambang dan diperkenalkan kembali dalam posisi yang baru.

Mieтри Buyuk sebagai ritus peralihan. Peralihan yang terjadi pada beberapa pelaku ritual adalah perubahan seseorang yang awalnya hanya seorang masyarakat biasa menjadi seseorang yang telah siap menjalankan ritual. Peralihan yang terjadi pada perlengkapan dan tempat ritual adalah ketika perlengkapan dan tempat awalnya sering digunakan untuk kegiatan sehari-hari, namun saat ritual mengalami kesakralan. Peralihan ini terjadi pada masing-masing elemen, terutama ikinsai. Ikinsai artinya ialah menari. Menari itu sendiri jika diperhatikan dari elemen dasar tari yaitu gerak, merupakan gerak extraordinary, gerak yang 'tidak biasa' dilakukan dalam perilaku sehari-hari. Peralihan ikinsai terjadi ketika ikinsai pada bagian inti pengobatan dalam Міетри Виуик, yakni Ikinsai saat Wadian Dadas akan mengalami itun alah.

Berdasarkan uraian Miempu Buyuk di atas memunculkan beberapa pertanyaan. Bagaimana Міетри Buyuk yang dilakukan oleh Wadian Dadas mencerminkan ritus peralihan? Jika beberapa elemen dalam Miempu Buyuk dijelaskan, apakah elemen tersebut akan mengalami peralihan? Perubahan apa yang terjadi pada masing-masing elemen yang mempresentasikan ritus peralihan? Kapan masing-masing elemen masuk pada bagian separation, transition (liminal), dan reintegration? Bagaimana Miempu Buyuk mencerminkan sebuah ritus peralihan? Apa makna ikinsai yang dilakukan oleh Wadian Dadas dalam Miempu Buyuk dari awal sampai akhir?

\section{PEMBAHASAN}

\section{A. Pendekatan Penelitian}

Masyarakat Barito Timur menganggap Miempu Buyuk sebagai suatu ritual yang penting dalam kehidupan sehari-hari. Masyarakat percaya Miempu Buyuk sebagai perantara untuk berkomunikasi dengan roh leluhur untuk meminta bantuan kesembuhan bagi seseorang yang sedang mengalami sakit. Sudut pandang emik digunakan untuk mendapatkan data yang sesuai fakta di lapangan. Masyarakat tentu memiliki pemahaman tentang peristiwa-peristiwa Miempu Buyuk yang dialaminya secara langsung. Peneliti juga melihat Miempu Buyuk dari cara pandang sendiri. Peneliti dapat memiliki argumen dan melogikakan suatu proses Miempu Buyuk dan harus memahami keterkaitan antar elemen. Adanya suatu pandangan terhadap ritual yang dilakukan oleh masyarakat, bahwa peneliti dapat beradaptasi dan bersosialisasi dengan lingkungan masyarakat Barito Timur agar dapat menjelaskan fenomena yang ada dalam masyarakat. Peneliti menggunakan sudut 
pandang etik untuk mendapatkan data yang akan dianalisis dengan cara interpretasi.

Penelitian ini menggunakan perspektif antropologi. Perspektif antropologi menekankan cara pandang yang bersifat emik dan etik. Melalui sudut pandang emik, peneliti dalam penggunaan etik dapat terbantu oleh penjelasan masyarakat yang telah mengalami peristiwa kehidupan. Fenomena dari sudut pandang emik maupun etik dapat dipadukan untuk melihat peristiwa yang terjadi. Dalam perspektif antropologi terdapat banyak konsep yang dikemukakan oleh para ahli antropologi. Salah satu tokoh yang memiliki konsep dan digunakan dalam penelitian ini adalah konsep tentang ritus peralihan oleh Victor Turner. Victor Turner juga mengadopsi dan mengembangkan kerangka berpikir dari Arnold Van Gennep. ${ }^{3}$

Pada penjelasannya, ada tiga fase dalam proses ritual yang berstruktur. Fase tersebut adalah separation (pemisahan), transition (liminal), dan reintegration (penyatuan kembali). Separation adalah masa perpisahan yang dimulai dari posisi lama dalam waktu normal. Ada tanda untuk membedakan ketika seseorang akan mengalami fase ini sebagai pemisah dari masyarakat biasa. Transition atau lebih dikenal dengan liminal melibatkan sesuatu yang sudah tidak berada pada posisi lama dan

${ }^{3}$ Victor Turner, 2013, Dari Ritual Ke Teater: Antropologi Pertunjukan, terjemahan St. Hanggar Budi Prasetya, Badan Penerbit ISI Yogyakarta, Yogyakarta: 6. belum menjadi baru. Dalam pembahasan selanjutnya, di antara penyebutan transition atau liminal yang digunakan adalah penyebutan liminal. Dalam penjelasannya, juga dibahas mengenai fase liminoid. Fase liminoid merupakan keadaan atau kondisi alternatif dari tatanan yang mapan berupa aktivitas-aktivitas yang jauh lebih terbatas, lebih bersifat mainmain, dan lebih terbuka pada kemungkinan. Reintegration terjadi ketika sesuatu yang lama telah melewati masa ambang atau liminal dan diperkenalkan kembali dalam posisi yang baru. Keadaan seseorang akan berubah status sosialnya ataupun kembali dalam kehidupan masyarakat setelah melakukan sebuah ritual. Berdasarkan konsep Victor Turner, Miempu Buyuk yang dilakukan oleh Wadian Dadas dapat dipandang sebagai sebuah Ritus Peralihan. Peristiwa tersebut dilihat dari beberapa elemen yang dapat dibedah menggunakan tiga fase ritus peralihan.

\section{B. Miempu Buyuk sebagai Ritus Peralihan}

Penelitian ini akan merujuk pada ritus peralihan. Ritus peralihan mengubah kondisi seseorang dari kondisi tertentu ke kondisi yang lain. Ritus peralihan adalah sebuah ritual untuk menghantarkan sesuatu, seseorang, wilayah, ataupun keadaan dari satu posisi ke posisi yang lain. Мiempu Buyuk suku Dayak Ma'anyan akan 
mengubah kondisi seseorang ke kondisi yang lain. Tak hanya untuk pelaku ritual saja, kondisi perlengkapan ritual dan tempat pelaksanaan ritual juga akan berubah. Keseluruhan Miempu Buyuk ini, akan membawa pada persoalan ikinsai yang akan dibahas lebih spesifik. Berikut penjelasannya:

\section{Miempu Buyuk}

a. Separation

Separation merupakan masa perpisahan. Semua elemen dipersiapkan untuk dapat terlibat dalam Miempu Buyuk. Pada bagian ini, muncul tanda-tanda pemisahan. Proses Miempu Buyuk diawali ketika Wadian Dadas didukung oleh pemimpin kebaktian Kaharingan serta masyarakat untuk melaksanakan pengobatan. Bagian separation ditandai saat dimulainya kebaktian Kaharingan, sebab bagian ini merupakan awal ritual akan dilaksanakan. Ketika kebaktian Kaharingan, Wadian Dadas diberi tendrek pada bagian dahi. Wadian Dadas memisahkan diri dari masyarakat untuk mencari tempat berganti pakaian di luar rumah. Wadian Dadas kembali ke ruang tengah untuk menggunakan minyak pada bagian tangan dan kepala, lalu menggunakan tendrek pada bagian dahi, pipi kanan kiri, bahu kanan kiri, dan di antara bahu. Setelah menggunakan minyak dan tendrek, Wadian Dadas memakai selendang dan gelang. Usai menggunakan semua kelengkapan, Wadian Dadas dapat melakukan miampamai ('memanggil' roh-roh leluhur dari pulau Kambang) melalui iwai. Pada saat proses 'pemanggilan' roh leluhur, Wadian Dadas meniup taring beruang serta meletakkan beberapa sesaji di mangkuk kecil di kepala. Sebelum menjalani proses ini, Wadian Dadas belum dapat menjalankan ritual. Wadian Dadas harus 'memanggil' roh leluhur agar dibantu dan diberikan perlindungan dalam pelaksanaan Miempu Buyuk.

Tanda yang muncul pada orang yang sakit, ketika Wadian Dadas menaburkan beras ke seluruh ruang. Orang yang sakit diperkenankan untuk bergabung menjadi satu dalam ritual. Masyarakat yang hadir juga ditandai saat penaburan beras ke seluruh ruang. Anggota masyarakat Desa Dorong yang ikut serta dalam pelaksanaan Miempu Buyuk seperti pemimpin kebaktian, pemusik, dan orang-orang penting lainnya diberikan beras di bagian kepala. Pemberian beras tersebut sebagai tanda hormat karena ikut membantu pelaksanaan Miempu Buyuk. Tanda-tanda inilah sebagai tanda awal pemisahan. Wadian Dadas, orang yang sedang sakit, 
dan warga yang hadir memiliki masa perpisahan masing-masing sebagai tanda awal akan terlihat dalam pelaksanaan Miempu Buyuk.

\section{b. Transition (Liminal)}

Liminal Mіетри Buyuk ditandai saat itun alah. Saat itun alah, seluruh elemen dan pelaku lebih dekat dengan roh leluhur. Wadian Dadas melakukan ikinsai sebagai penghubung proses Miempu Buyuk. Setiap akan melakukan tahapan, Wadian Dadas akan ikinsai untuk berpindah dari tahapan satu ke tahapan lainnya (ruang antar ruang).

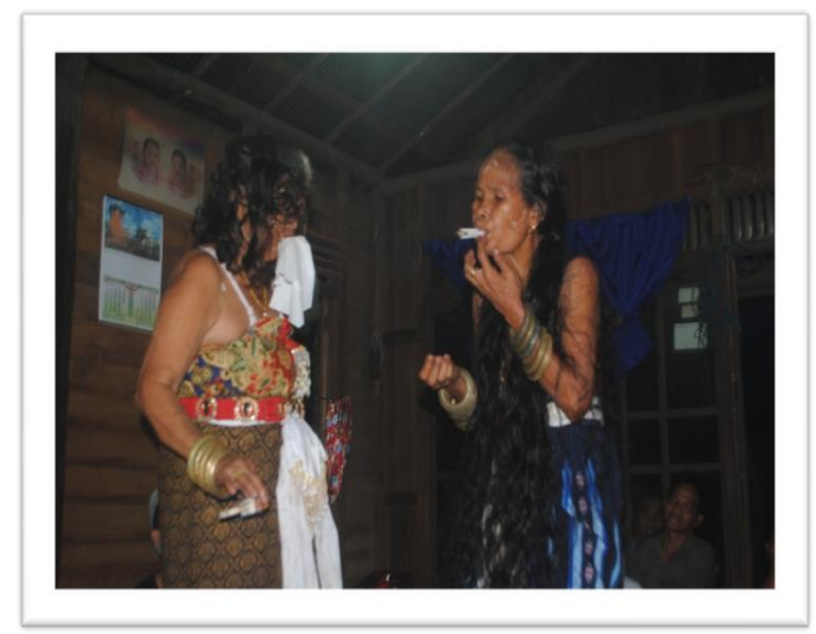

Gambar 1. Ineh Lambuk (sarung kurung berwarna cokelat) dan ineh Rantan (sarung kurung berwarna biru) mengalami itun alah

(Foto: Debbi di Desa Dorong, Barito Timur, 02 Februari 2018)

Melalui ikinsai, Wadian Dadas akan itun alah, kemudian mengambil tumbuhan segar sebagai obat dalam keadaan itun alah dan menghantar roh orang sakit melalui balai. Keadaan Wadian Dadas saat proses ikinsai sebagai situasi liminal ketika Wadian Dadas melakukan penyembuhan yang dibantu oleh roh leluhur. Wadian Dadas berada di ambang batas, antara ada di dunia nyata dan berkomunikasi dengan roh leluhur di alamnya untuk meminta petunjuk.

Orang yang sedang sakit diberi Wadian Dadas tumbuhan yang didapatkan. Melalui tiga balai, Wadian Dadas berkomunikasi dengan roh leluhur untuk meminta bantuan menyembuhkan orang sakit. Walaupun orang yang sedang sakit telah diberi obat, namun orang sakit tersebut masih berada pada situasi liminal karena dalam tahap penyembuhan. Masyarakat yang ikut berpartisipasi masih dalam keadaan diambang, sebab masih merasakan peristiwa ritual. Masyarakat dalam pelaksanaan ritual ini, belum kembali dalam kehidupan sehari-hari. Pada bagian ini, posisi liminal dalam Miempu Buyuk saat ikinsai sebagai sarana meminta bantuan dengan roh leluhur.

\section{c. Reintegration}

Pada tahap penyatuan kembali, ditandai saat proses memulangkan (mengembalikan) roh leluhur melalui iwai ke pulau Kambang menandakan Miempu Buyuk telah selesai. Usai pelaksanaan Miempи Buyuk, tidak lagi bersatu dengan kepercayaan Kaharingan, melainkan 
kembali pada kepercayaan masingmasing. Wadian Dadas dan masyarakat percaya bahwa setelah pelaksanaan Miempu Buyuk ini, mereka terhindar dari roh jahat dan diberikan keselamatan.

Seseorang yang sakit tersebut berhasil disembuhkan jika Wadian Dadas mengambil tumbuhan segar. Melogikakan dari pola kehidupan mereka yang terletak di wilayah hutan, memiliki keanekaragaman tumbuhan yang dapat dijadikan sebagai obat. Tumbuhan yang diambil oleh Wadian Dadas diyakini dapat menyembuhkan orang yang sedang sakit. Seseorang yang disembuhkan pun dapat bergabung kembali dengan masyarakat. Masyarakat yang ikut berpartisipasi, kembali dalam kehidupan sehari-hari setelah selesai mengikuti ritual. Mereka meyakini, setelah proses Miempu Buyuk dapat diberikan keselamatan dan terhindar roh jahat.

\section{Wadian Dadas}

a. Separation

Seorang Wadian Dadas sebelum memimpin ritual berprofesi sebagai masyarakat biasa. Ketika akan memasuki proses ritual, Wadian Dadas akan mempersiapkan secara mental dan fisik, tak benda maupun benda. Umur Wadian Dadas yang sudah lanjut usia, membuat Wadian Dadas harus mempersiapkan stamina yang lebih banyak. Kesehatan dan kesiapan segala kelengkapan lebih diperhatikan agar proses pengobatan berjalan dengan lancar. Saat ritual berlangsung, Wadian Dadas akan berganti pakaian di luar rumah. Wadian Dadas akan kembali ke dalam rumah untuk menggunakan tendrek. Posisi Wadian Dadas sebelum siap memimpin ritual sampai kondisi mempersiapkan diri dan memisahkan diri untuk berganti pakaian bagian dari masa perpisahan. Tendrek ditandai Wadian Dadas telah siap melakukan perjalanannya menempuh ritual. Saat itu memisahkan diri dari masyarakat untuk berganti pakaian, Wadian Dadas pertama kali 'meminta' perlindungan roh leluhur. Setelah mengenakan pakaian, perlengkapan, dan tendrek, Wadian Dadas dapat dikatakan telah berpisah dari masyarakat. Wadian Dadas bukan seperti wanita biasa yang melakukan kegiatan sehari-hari.

b. Transition (liminal)

Usai setelah itu, Wadian Dadas akan memasuki masa ambang ketika akan melanjutkan ritual. Wadian Dadas berada di dua dunia, yakni dunia nyata dan berkomunikasi dengan roh leluhur di alamnya. Tak hanya itu, Wadian Dadas akan mengalami itun alah untuk mengambil obat melalui bantuan roh 
leluhur. Kondisi ini, posisi Wadian Dadas mengalami masa liminal atau ambang, tidak di dunia nyata namun berada di dunia nyata.

c. Reintegration

Wadian Dadas akan kembali menjadi masyarakat biasa saat ritual selesai dilaksanakan. Wadian Dadas memasuki masa penyatuan kembali dengan orangorang yang berada di sekelilingnya. Hal ini ditandai dengan 'memulangkan' roh leluhur. Setelah memulangkan, Wadian Dadas merapikan segala perlengkapannya dan menghapus tendrek. Demikian, Wadian Dadas akan menjadi masyarakat biasa dan tidak dibedakan dengan yang lain. Wadian Dadas sehabis menjalankan ritual lebih banyak istirahat di rumah untuk memulihkan energi. Mereka merasa lega dapat menyelesaikan tugas.

\section{Orang Sakit}

a. Separation

Orang sakit merupakan salah satu pendukung penting dalam suatu ritual pengobatan. Tanpa ada orang sakit, maka tidak dapat dikatakan ritual pengobatan. Orang sakit akan mengalami suatu persiapan diri untuk meminta ritual. Orang sakit merasa siap dan yakin bahwa melalui Miempu Buyuk akan mendatangkan kesembuhan. Setelah yakin, orang sakit akan datang kepada Wadian Dadas untuk diritualkan. Kondisi ini menandakan orang sakit mengalami masa perpisahan ketika dirinya telah dipersiapkan terlebih dahulu sebelum proses penyembuhan berlangsung. Kesiapan untuk menjalankan proses penyembuhan akan ditindak lanjutkan dalam suatu pelaksanaan Miempu Buyuk.

b. Transition (Liminal)

Selama proses Miempu Buyuk berlangsung, orang sakit akan mengalami masa ambang. Orang sakit tidak akan mengetahui tumbuhan yang akan diambil oleh Wadian Dadas. Kemungkinan yang terjadi, Wadian Dadas mengambil tumbuhan segar atau tumbuhan kering. Kondisi ini membuat orang sakit berada 'di antara' sembuh atau tidak. Jika tumbuhan segar yang diambil menandakan dapat disembuhkan, namun jika tumbuhan kering yang diambil menandakan terjadi bahaya. Situasi ambang berada dalam jiwa orang sakit, antara ketenangan dan kegelisahan sebelum Wadian Dadas dapat menyembuhkan.

c. Reintegration

Saat pelaksanaan Miempu Buyuk ini, Wadian Dadas berhasil mengambil tumbuhan segar. Hal ini menandakan orang sakit memasuki masa penyatuan kembali. Kondisi orang sakit yang 
awalnya dalam keadaan tidak sehat, berubah menjadi sehat. Orang sakit dapat disembuhkan melalui perantara Wadian Dadas dalam pelaksanaan Miempu Buyuk. Orang sakit dapat bergabung dengan masyarakat lain dalam kondisi sehat dan keadaan dalam tenang. Orang yang sakit merasa lebih santai dan tidak terbebani lagi.

\section{Panganak Hiang}

a. Separation

Panganak hiang salah satu yang menemani Wadian Dadas untuk membantu segala kesiapan dan kelengkapan ritual. Sebelum memasuki ritual, panganak hiang hanya seorang ineh biasa. Setelah diminta untuk membantu ritual, panganak hiang akan berada dalam masa pemisah. Panganak hiang mempersiapkan tenaga untuk dapat menyelesaikan dan melaksanakan tugas dengan baik. Persiapan batin dan tenaga yang dilakukan menadakan panganak hiang telah melakukan pemisahan diri. Masa pemisah ditandai saat panganak hiang tiba di rumah ineh Rantan untuk melaksanakan tugas.

b. Transition (Liminal)

Ketika memasuki masa ritual, panganak hiang akan mempersiapkan segala kelengkapan sejak pagi hari. Selain itu, panganak hiang akan tetap membantu sampai ritual berakhir. Posisi liminal panganak hiang berada saat mempersiapkan segala kelengkapan ritual, panganak hiang akan merasa antara sudah lengkap atau belum lengkap. Sementara itu selama proses ritual berlangsung, panganak hiang tidak berada dalam kondisi biasanya, tetapi dalam kondisi nyata. Panganak hiang tidak mempersiapkan kelengkapan dalam kehidupan sehari-hari, namun mempersiapkan kelengkapan ritual dalam kehidupan nyata. Ketika itu, posisi liminal panganak hiang terjadi saat ritual sedang berlangsung. Posisi ini menandakan panganak hiang mengalami masa ambang.

c. Reintegration

Usai ritual dilaksanakan, tidak ada kekurangan dalam pelasanaan Miетри Buyuk. Panganak hiang merasa tenang dan aman bahwa segala usahanya tidak sia-sia. Panganak hiang yaitu ineh Mariyana dapat menjadi seorang ibu kembali dalam kehidupan sehari-hari tanpa terikat dengan ritual dengan perasaan damai. Setelah selesai menjalakan tugas, ineh Mariyana merasakan kelegaan. Penyatuan kembali terjadi saat panganak haiang telah pulang ke rumahnya. 


\section{Pemusik}

a. Separation

Pemusik saat pelaksanaan Miempu Buyuk ini dari sanggar Komandan. Masa perpisahan ditandai dengan kesediaan mereka menjalankan tugas sebagai pengiring Міетри Buyuk. Masa perpisahaan pemusik saat mereka telah berada di rumah ineh Rantan untuk menjalankan tugas mengiringi ritual.

b. Transition (Liminal)

Ketika dalam prosesi, mereka dikenal sebagai pengiring Miempu Buyuk. Meraka berbeda dari biasanya saat menjalankan tugas di sanggar Komandan. Memasuki masa liminal, pemusik harus selalu ada sampai pelaksanaan Miempu Buyuk selesai. Pemusik tidak seperti pelaku sanggar Komandan lainnya yang dapat pergi jika merasa telah lelah. Pemusik berada dalam situasi ambang sebagai pengiring, namun bagian dari sanggar Komandan. Walaupun pemusik merasa lelah, tetapi memiliki tanggung jawab penuh untuk menyelesaikan tugas sampai ritual selesai. Posisi liminal terjadi saat pemusik membunyikan alat musik atau mengiringi ritual saat ritual berlangsung.

c. Reintegration

Kondisi ini akan membawa pemusik pada penyatuan kembali. Ketika Miempu Buyuk berakhir, pemusik tidak lagi terikat sebagai pengiring. Pemusik merasa tanggung jawabnya telah terselesaikan. Mereka dapat bergabung kembali dengan sanggar Komandan untuk menjalankan aktivitas sanggar sehari-hari. Kondisi penyatuan kembali ditandai saat pemusik telah kembali ke rumah masing-masing dan menjalankan tugasnya di Sanggar Komandan.

\section{Perlengkapan Ritual}

a. Separation

Perlengkapan ritual merupakan kebutuhan yang selalu disediakan dalam Міетри Bиуик. Perlengkapan ritual sebelum memasuki proses Мiempи Виуиk hanya sebatas benda maupun makanan biasa. Perlengkapan belum memiliki arti secara spesifik. Ketika memasuki masa ritual, perlengkapan akan menjadi elemen penting. Posisi pemisah perlengkapan ritual terjadi ketika dimulai kebaktian Kaharingan.

b. Transition (Liminal)

Posisi perlengkapan saat berlangsungnya Miетри Buyuk, masuk dalam situasi liminal. Perlengkapan benda maupun makanan akan menjadi sakral dan tidak sama seperti sebelum ritual. Perlengkapan tidak dapat sembarang digunakan maupun disantap. Kondisi perlengkapan sama seperti sehari-hari, namun tidak dapat dipergunakan sesuka 
hati. Kesakralan perlengkapan berada 'di antara' dunia nyata, tetapi sudah memiliki peran masing-masing dalam pelaksanaan Miempu Buyuk. Posisi liminal perlengkapan terjadi saat ritual dimulai atau ritual berlangsung.

c. Reintegration

Saat Miempu Buyuk telah usai dilaksanaan, posisi penyatuan kembali terjadi saat perlengkapan telah dibersihkan. Perlengkapan boleh dipergunakan kembali untuk kebutuhan sehari-hari maupun disimpan. Perlengkapan yang disimpan dapat dipergunakan kembali saat akan diadakan ritual.

\section{Tempat Pelaksanaan Ritual}

a. Separation

Tempat pelaksaan ritual sama halnya dengan perlengkapan ritual akan merujuk pada suatu kesakralan. Tempat pelaksanaan ritual, yakni rumah ineh Rantan sebatas rumah sebagai tempat tinggal. Rumah seperti yang diketahui untuk tempat beristirahat, bersantai, berkumpul keluarga, dan tempat menjalankan aktivitas sehari-hari. Rumah dapat digunakan sesuai keinginan pemiliknya. Ketika pelaksanaan Miempu Buyuk berlangsung, rumah sebagai tempat pelaksanaan ritual tidak dapat dipergunakan sesuka hati. Posisi pemisah tempat pelaksanaan ritual terjadi saat warga Desa Dorong datang untuk membantu mempersiapkan kelengkapan ritual.

b. Transition (Liminal)

Jika apapun perlengkapan ritual seperti sesaji maupun balai telah disediakan di posisi masing-masing, ruang tersebut tidak dapat diinjak maupun digunakan. Peristiwa ini merupakan situasi liminal yang terjadi pada tempat pelaksanaan ritual. Posisi liminal tempat pelaksanaan ritual terjadi ketika ritual sedang berlangsung dan saat proses inti (pengobatan). Walaupun sebatas rumah biasa, tempat pelaksanaan akan berada 'di antara' kesakralan seiring berlangsungnya Miempu Buyuk. Kondisi ini menandakan tempat telah siap dalam keadaan liminal.

c. Reintegration

Posisi penyatuan terjadi saat Wadian Dadas, orang sakit, panganak hiang, dan warga Desa Dorong yang masih hadir sedang makan dan memberikan ucapan terima kasih. Ketika itu, mereka boleh menggunakan tempat sesuai dengan keinginan. Usai berjalannya ritual, tempat akan kembali dalam keadaan seperti semula. Tempat dapat menyatu dengan pemilikinya dalam maksud menjadi tempat menjalankan kehidupan seharihari. Usai pelaksanaan Miетри Buуик, 
menandakan tempat sudah berubah dari kondisi sakral sampai kembali menjadi tidak sakral.

\section{Ikinsai sebagai Ritus Peralihan}

1. Separation: Ikinsai ketika 'pemanggilan' roh leluhur

Miempu Buyuk terdiri dari tiga bagian, yakni bagian awal pembukaan, inti pengobatan, dan akhir penutup. Pada tiga bagian ini ada ikinsai sebagai salah satu elemen penting. Ikinsai terbagi menjadi tujuh bagian proses ikinsai. Ikinsai dalam Miempu Buyuk mencerminkan ritus peralihan.

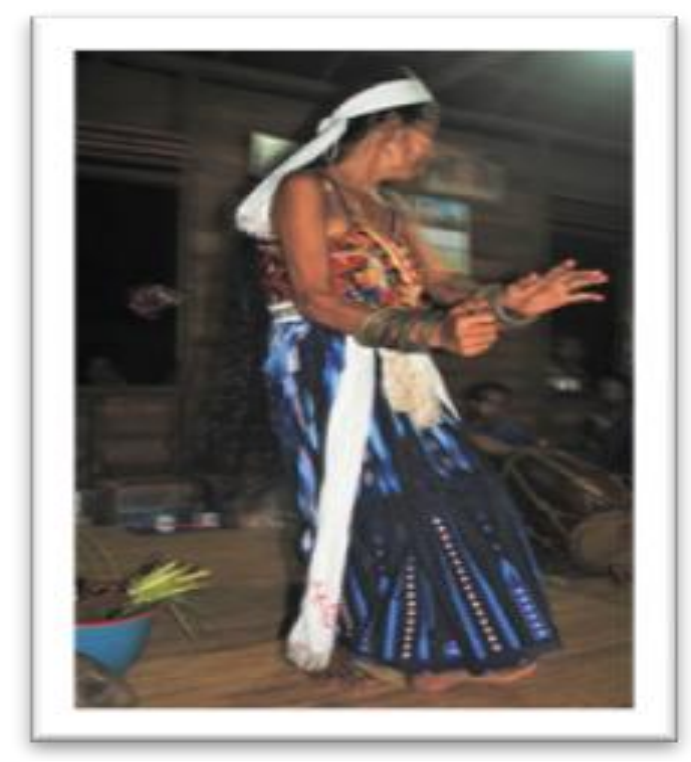

Gambar 2. Ineh Rantan ketika ikinsai (Foto: Debbi di Desa Dorong, Barito Timur, 02 Februari 2018)

Ikinsai dilakukan oleh Wadian Dadas saat penaburan beras dan pemanggilan roh leluhur. Ketika penaburan beras ikinsai belum berkaitan dengan roh leluhur. Setelah itu, Wadian Dadas memanggil roh leluhur melalui iwai. Setelah memegang iwai, Wadian Dadas berdiri untuk melakukan ikinsai. Wadian Dadas melakukan ikinsai di teras rumah dan di dalam rumah. Pada bagian ini tampak posisi pemisah dari ikinsai tersebut. ikinsai sudah ada hubungan dengan roh leluhur yang berbeda dari ikinsai sebelumnya, maka ikinsai terpisah dari ikinsai sebelumnya.

2. Liminal: Ikinsai ketika itun alah dan proses tiga balai

Ikinsai saat itun alah dan proses tiga balai dapat dikatakan bagian liminal. Ketika itun alah, ikinsai tersebut digerakkan oleh roh leluhur. Ikinsai tidak dapat terkendalikan, sebab tempo ikinsai cepat dan muncul gerak-gerak improvisasi. Gerak tersebut tidak seperti gerak pada bagian lainnya, namun masih tampak gerak menggunakan gelang. Keberadaan ini yang menandakan liminal, ikinsai tidak seperti biasanya, tetapi masih berkaitan dengan gelang. Selanjutnya, bagian liminal pada ikinsai juga tampak pada proses tiga balai. Ikinsai sebagai sarana atau penghubung Wadian Dadas dari iwai menuju setiap balai. Ikinsai juga sebagai perantara meminta bantuan untuk menjaga roh orang-orang agar tidak itun alah. Tanpa ikinsai, Wadian Dadas tidak 
akan menuju ke tiga balai. Peran ikinsai ini merupakan bagian dari liminal.

3. Reintegration: Ikinsai ketika 'pengembalian' roh leluhur

Penyatuan kembali pada ikinsai tampak saat Wadian Dadas telah mengembalikan roh leluhur. Wadian Dadas memegang iwai untuk memulangkan roh leluhur, setelah itu dilanjutkan dengan ikinsai. Ikinsai tersebut tidak lagi memiliki hubungan dengan roh leluhur, sebab ikinsai dilakukan dalam keadaan normal. Ikinsai telah melewati masa pemisah saat memanggil roh leluhur untuk meminta bantuan dan melewati masa ambang saat ikinsai digerakkan oleh roh. Hal ini menandakan ikinsai beralih menjadi biasa tanpa roh leluhur.

\section{Ikinsai sebagai Liminoid}

Pandangan Victor Turner tentang liminoid dapat dipahami sebagai sebuah tahapan ritual. Menganalisis suatu ritual selain meminjam konsep Turner, peneliti dapat memberikan asumsi tambahan untuk mempertegas penelitian. Dalam pandangan ritus peralihan, maka ikinsai merupakan fase liminoid. Perbedaan antara fase liminal dan liminoid, yakni fase liminal merupakan sesuatu yang sudah tidak berada dalam posisi lama, namun belum baru, berada di antara. Liminoid berasal dari bahasa
Yunani yang diambil dari kata oid-eidos, bentuk yang berarti seperti atau menyerupai. ${ }^{4} \quad$ Fase Liminoid antara meninggalkan satu posisi dan mengambil yang lain, baik dalam hal subjek, untuk orang-orang yang ia tinggalkan dan bergabung. ${ }^{5}$ Keadaan yang berada di 'antara' terdapat subjek yang menjadi suatu tindakan liminoid.

Secara singkat, liminal ke liminoid dapat dipahami sebagai suatu situasi ambang pada ruang lingkup ritual yang di dalamnya lebih bersifat bermainmain. Liminal akan membawa pada persoalan liminoid. Liminal Miempu Buyuk ditandai dengan proses Wadian Dadas menyembuhkan orang sakit melalui perantara roh leluhur. Proses ini berada pada situasi ambang batas, antara berada dalam kehidupan nyata, tetapi berhubungan dengan roh leluhur di alamnya. Dalam prosesi ini, terjadi suatu pergelaran yang dapat menjadi tontonan. Pergelaran tersebut hadir ketika Wadian Dadas melakukan ikinsai dan menjadi itun alah. Ikinsai Wadian Dadas dilakukan dengan mendadaskan gelang dan memakai selendang. Ikinsai gelang

${ }^{4}$ Victor Turner terjemahan St. Hanggar Budi Prasetya, 2013, Dari Ritual Ke Teater: Antropologi Pertunjukan, Yogyakarta: Badan Penerbit ISI Yk, 20.

${ }^{5}$ Victor Turner terjemahan St. Hanggar Budi Prasetya, 2013, Dari Ritual Ke Teater: Antropologi Pertunjukan, Yogyakarta: Badan Penerbit ISI Yk, 20. 
dan selendang menyimbolkan gerakan binatang. Wadian Dadas melakukan ikinsai sebelum menjadi itun alah. Tempo ikinsai yang semakin cepat, menandakan bahwa Wadian Dadas akan itun alah. Ketika itun alah, Wadian Dadas terkadang melakukan tindakan yang tidak wajar. Tindakan Wadian Dadas tersebut dapat menghibur masyarakat. Masyarakat secara tidak sengaja menonton aksi dari Wadian Dadas tersebut. proses liminal dalam pelaksanaan Miempu Buyuk, terdapat ikinsai yang menjadi persoalan liminoid. Peristiwa ini yang menandakan perpindahan dari liminal ke liminoid dalam Miempu Buyuk.

Suatu pelaksanaan Miempu Buyuk telah membingkai ikinsai sebagai sarana penting dalam pengobatan. Liminoid yang terjadi dalam ikinsai, bukan sekedar genre hiburan, melainkan salah satu elemen yang tidak dapat dilepas. Wadian Dadas mendadaskan gelang agar dapat terlindungi dari roh jahat dan dibantu oleh roh leluhur. Setiap pentahapan, Wadian Dadas melakukan ikinsai. Melalui ikinsai, roh leluhur akan masuk ke dalam jiwa Wadian Dadas. Roh leluhur akan memberikan petunjuk untuk mengambil obat yang dirasa tepat. Proses ikinsai diyakini sebagai sarana pengobatan utama dalam pelaksanaan Miempu Buyuk.
Berikut penjelasan lebih lanjut mengenai masing-masing makna tujuh ikinsai.

Keberadan ikinsai ada pada tiga proses Miempu Buyuk. Pada bagian pembukaan, ikinsai sebagai awalan untuk memulai ritual. Pada bagian inti pengobatan, ikinsai sebagai cara untuk membantu Wadian Dadas menemukan obat yang telah dipilih. Pada bagian penutup, ikinsai sebagai akhir ritual bahwa Miетри Виуuk telah selesai dilaksanakan. Oleh sebab itu, ikinsai merupakan sarana atau penghubung ritual dari satu tahapan ke tahapan yang lain. Keseluruhan ikinsai dapat dipahami ada keterkaitan dari setiap tahapan, karena setiap tahap ikinsai sebagai penghubung dengan roh leluhur ketika gelang didadaskan supaya terhindar dari roh jahat.

1. Ikinsai Penaburan Beras

Ikinsai dilakukan sebagai sarana penghubung menaburkan beras kepada pelaku ritual dari satu pelaku ke pelaku lainnya. Ikinsai saat penaburan beras sebagai tanda hormat kepada pelaku penting yang hadir. Beras sebagai bahan yang digunakan untuk menabur adalah kebutuhan pokok dalam kehidupan seharihari sebagai simbol kemakmuran. Ikinsai penaburan beras memiliki makna bahwa ikinsai sebagai jalan pokok agar pelaku 
ritual dipandang memiliki kehormatan dalam pelaksanaan ritual.

\section{Ikinsai 'Pemanggilan' Roh Leluhur}

Ikinsai saat 'pemanggilan roh leluhur ditandai sebagai cara berkomunikasi dengan roh leluhur. Setalah iwai digoyangkan dan dibacakan doa, Wadian Dadas langsung melakukan ikinsai dengan mendadaskan gelang.

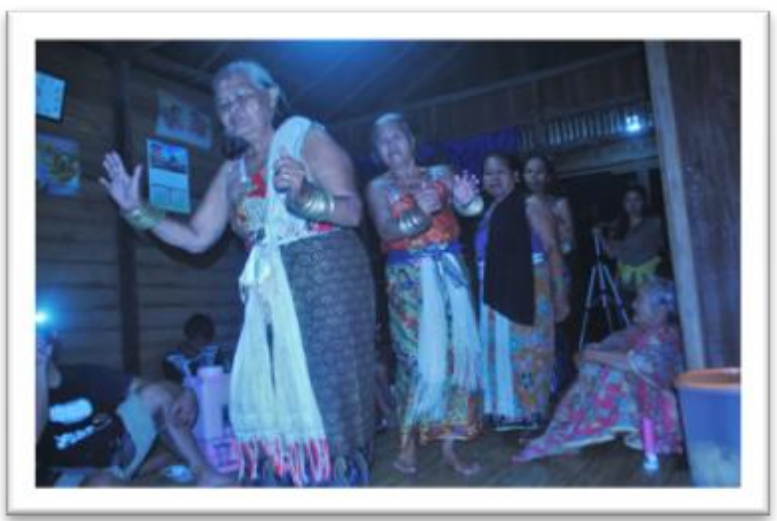

Gambar 3. Ikinsai oleh Wadian Dadas

(Foto: Debbi di Desa Dorong, Barito Timur, 02 Februari 2018)

Ikinsai tersebut memiliki makna bahwa bunyi dari mendadaskan untuk 'membangunkan' roh leluhur agar datang membantu Wadian Dadas menjalankan proses ritual dari awal sampai akhir ritual. Ikinsai ini supaya cocok dengan roh leluhur. Maksud dari cocok adalah roh leluhur mau menerima pelaku ritual.

3. Ikinsai Itun Alah

Ikinsai saat itun alah menandai sebagai sarana penghubung dengan roh leluhur. Ikinsai dilakukan oleh Wadian Dadas berulang kali, sehingga tempo gerak semakin cepat. Semakin cepat tempo yang dilakukan, tampak gerak saat ikinsai menjadi improvisasi. Hal ini menandakan Wadian Dadas mengalami itun alah. Makna yang terkandung dalam ikinsai ini bahwa roh leluhur masuk ke jiwa Wadian Dadas untuk mengobati orang sakit. Wadian Dadas digerakkan oleh roh leluhur untuk mengambil tumbuhan sebagai obat.

4. Ikinsai Balai Saruga

Ikinsai di balai Saruga sebagai perantara Wadian Dadas dengan roh leluhur. Bagian ini bermakna bahwa Wadian Dadas 'mengambil' roh leluhur untuk membantu dalam pengobatan. Oleh sebab itu, Wadian Dadas melakukan proses di balai Saruga agar roh leluhur tetap hadir untuk melanjutkan ritual.

5. Ikinsai Balai Akar Jawa

Ikinsai di balai Akar Jawa untuk 'mengambil' roh leluhur dan menjaga roh orang hidup. Roh leluhur dijaga agar tetap hadir, sedangkan roh orang hidup dijaga agar terhindar dari bahaya dan tidak mengalami itun alah. Menjaga roh orang hidup dapat dipahami bahwa roh orang hidup terutama untuk orang sakit akan dihantarkan kepada roh leluhur agar orang sakit tidak diganggu roh jahat lagi.

6. Ikinsai Balai Papai

Ikinsai di balai Papai hanya untuk menjaga roh orang hidup. Ikinsai yang 
dilakukan mengelilingi balai Papai.

Dengan demikian, mendadas yang

dilakukan oleh Wadian Dadas akan menghindarkan jiwa-jiwa orang hidup dari roh jahat. Jiwa orang yang sebelumnya mengalami sakit, dijauhkan dari roh jahat.

\section{Ikinsai ‘Pengembalian' Roh Leluhur}

Ketika 'memanggil' roh leluhur, akan ada 'mengembalikan' roh leluhur. Wadian Dadas memegang iwai dan menggoyangkannya sambil membacakan doa untuk 'memulangkan' roh leluhur. Setelah itu, Wadian Dadas melanjutkan dengan melakukan ikinsai. Ikinsai menandakan bahwa ritual telah selesai. Ikinsai dimaknai sebagai jalan roh leluhur untuk kembali ke tempat asalnya.

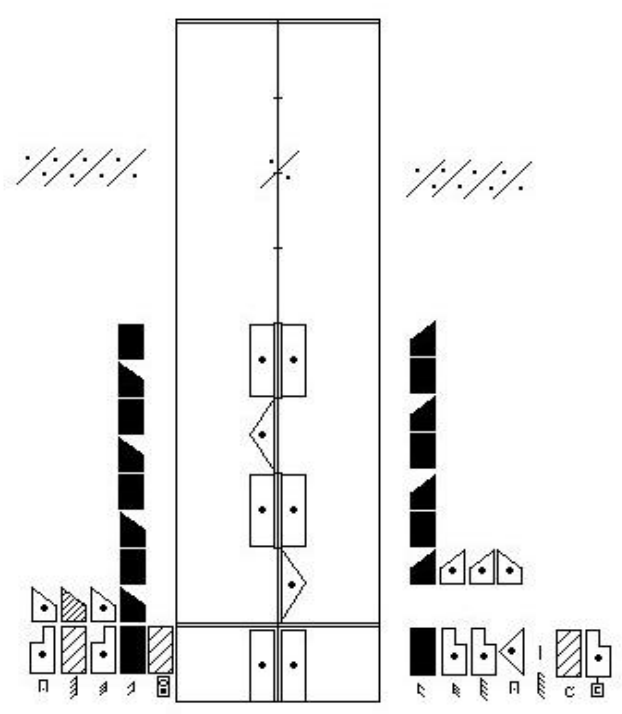

Gambar 4. Notasi Laban gerak pada ikinsai menggunakan gelang

\section{PENUTUP}

Suku Dayak Ma'anyan melakukan berbagai ritual sejak zaman nenek moyang. Ritual yang dijalankan oleh masyarakat suku Dayak Ma'anyan berkaitan erat dengan kepercayaan Kaharingan. Ritual yang berkaitan dengan tatanan Kaharingan ini, termasuk dalam kategori upacara keagamaan. Ritual tersebut disebut dengan mіетри (upacara ritual). Miempu suku Dayak Ma'anyan dipimpin oleh wadian. Wadian memiliki beberapa tingkatan, yakni Wadian Amunrahu, Wadian Tapu Ondru, Wadian Dapa, Wadian Bawo, dan Wadian Dadas.

Wadian Dadas memimpin Miempu Numang Wadian, Miempu Nahur Hajat, dan Miempu Buyuk. Miempu Buyuk merupakan upacara ritual pengobatan. Beberapa tahapan dalam pelaksanaan Miempu Buyuk, yaitu awal (pembukaan), inti (pengobatan), dan akhir (penutup). Prosesi ini tidak terlepas dari ikinsai. Ikinsai oleh Wadian Dadas menjadi perangkai bagian-bagian dari Miempu Buyuk. Tahapan-tahapan Miеmpu Buyuk mencerminkan sebuah ritus peralihan.

Мiетри Buyuk mengubah kondisi seseorang dari sakit menjadi sembuh, dari situasi pengobatan ke situasi kehidupan normal. Selain itu, elemen-elemen pada Miempи Buyuk seperti pelaku ritual lainnya, perlengkapan ritual, dan tempat pelaksanaan ritual, juga mengalami peralihan. Perubahan yang terjadi pada pelaku ritual di antaranya adalah Wadian Dadas, orang sakit, panganak hiang, dan pemusik. Perlengkapan ritual dan tempat pelaksanaan ritual yang awalnya hanya menjadi sesuatu yang biasa dalam kegiatan 
sehari-hari, kini saat pelaksanaan Miempu Buyuk berubah menjadi sakral. Hal tersebut disebabkan karena saat pelaksanaan, perlengkapan dan tempat tersebut menjadi salah satu elemen pendukung yang tidak dapat digunakan seperti sehari-hari.

Pada posisi liminal dalam proses Miempu Buyuk, di dalamnya tampak ikinsai yang dimaknai sebagai liminoid. Posisi liminal Miempu Buyuk merupakan proses inti dari pengobatan, ada ikinsai yang dimaknai sebagai sarana penghubung Wadian Dadas dengan roh leluhur agar mengalami itun alah untuk dapat mengambil tumbuhan. Selain itu, ikinsai juga dipandang sebagai ritus peralihan, yang tampak pada tujuh proses ikinsai. Posisi separation ada pada ikinsai 'pemanggilan' roh leluhur, posisi liminal ada pada ikinsai itun alah, dan posisi reintegration ada pada ikinsai 'memutangkan'roh leluhur.

\section{DAFTAR SUMBER ACUAN}

\section{A. Sumber Tertulis}

Hanna, Judith Lynne. 1987. To Dance Is Human. Chicago: University Of Chicago Press.

Moleong, Lexy J. 2007. Metodologi Penelitian Kualitatif. Bandung: PT Remaja Rosdakarya.

Novianto. 2011. "Jendela Borneo Membangun Kontruksi Pemahaman Terhadap Berbagai Realita Sosial, Politik, dan Kebudayaan
Sukun Bangsa Dayak". Sintang: Asta Prima.

Pemerintah Daerah Kabupaten Barito Timur. 2005. Sejarah dan Kahiyangan Wadian Dayak Ma'anyan Barito Timur. Palangka Raya: Pemerintah Daerah Kabupaten Baarito Timur.

Riwut, Tjilik . 2003. Maneser Panatau Tatu Hiang. Palangka Raya: Pusakalima.

Simatupang, Lono. 2013. Pergelaran: Sebuah Mozaik Penelitian Seni-Budaya. Yogyakarta: Jalasutra.

Turner, Victor, From Ritual To Theatre: The Human Seriousness Of Play diterjemahan oleh St. Hanggar Budi Prasetya. 2011. Dari Ritual Ke Teater: Antropologi Pertunjukan. Yogyakarta: Badan Penerbit ISI Yogyakarta.

\section{B. Narasumber}

Debbi Leriantoni, 36 tahun, seorang penari Wadian Bawo di Tamiang Layang, Kabupaten Barito, Kalimantan Tengah.

Rantan, 64 tahun, seorang Wadian Dadas di Desa Dorong, Tamiang Layang Kabupaten Barito Timur, Kalimantan Tengah.

Eka Nugrahno, 27 tahun, penari Wadian Bawo di Tamiang Layang, Kabupaten Barito Timur, Kalimantan Tengah. 